\title{
EDITORIAL
}

\section{ON GIVERS, RECEIVERS AND STAKEHOLDERS}

As many Shakespeare lovers will recall, "It is more blessed to give than to receive". And if university administrators or for that matter, scholars in quest of research grants-have pressing reasons for agreeing with Portia's eulogy on the quality of mercy, it remains a fact that universities have always relied on the generosity of the Prince, sometimes in person though more often in the form of his taxpaying subjects in whose name public finance is disbursed and dispensed. Universities in most parts of the world have been seen as part of public service and for this reason have been funded from the state budget. Indeed, the most spectacular development of higher education ever to have taken place in the history of that institution-whether in terms of the number of establishments founded or the number of students attending it-has been driven by public investment. If valid for both Western Europe and the United States-and one thinks here of the role played by the U.S. National Defense (Education) Bill of 1959 - this axiom is no less valid in the case of those nations emerging into full nationhood in the course of the late Fifties and early Sixties and particularly in Africa. Yet, if the transition from elite to mass higher education in Europe was achieved by massive injections of the nation's wealth into the task of bringing higher learning to a broader range of its young people, it is no less clear that such methods of funding carried within them the seeds of their own destruction. Put simply, it is not possible - even in the richest economies - to fund mass higher education on the same basis as its elite predecessor. Nor is this situation confined to the industrial economies of the Northern hemisphere. Financial squeeze and the press for students to fund their own studies are as evident in India as it is in Kenya as the contributions by Tilak and by Rodrigues and Wandiga make plain though in neither Kenya nor India is higher education even on the threshold of becoming a mass system.

\section{GIVING AND REPAYMENT}

Naturally, as governments introduced "financial compression" as an instrument of "system steering" and increasingly turned their attention to "cost recovery", so they sought to play down what an earlier generation might have regarded as a withdrawal from public responsibility. And equally naturally they sought to put a positive interpretation on such events. The shrinkage in institutional core funding was presented as an increase in institutional autonomy, as a test of initiative and as a Heavensent opportunity for the individual university to demonstrate efficiency and to give quantifiable proof of its enterprise. As with the 16th century sale of Indulgences, so with today's university:

"Als ein Munz im Koffer klingt

Ein Rektor aus dem Hoelle springt"

Like Portia's, it was a view which held that it was indeed more blessed for the 
individual to give than to be in receipt of subsidies and thrice blessed for the university to sign a contract with industry than to rely on government funding. As government core funding shrank, and universities looked for further sources of revenue, large numbers of student loan schemes were put in place in Australia, Britain and Kenya entre autres to enable erstwhile receivers to assume the hallowed status of "consumers" and givers. But as Tilak argues and Wandiga and Rodrigues explore in minute detail, whilst there is a certain moral superiority to be had in the principle of giving, it is a very different matter when it comes to "giving back".

The modern day adage of "consume now, pay later" may well be a necessary step in lightening the burdens on the public purse. And whilst it may be argued that the assumption by students of the cost of their study shifts the burden both from succeeding generations and from the public in general, towards the present generation of individual students, it is clear that the cost of administrating such schemes quite apart from the default rate, are issues of the nicest calculation, political as well as mathematical and actuarial.

\section{RISKY INVESTMENTS}

Yet, there are limits to the extent to which even the most entrepreneurial of students is willing to assume such a burden. Certainly, economists will argue that self selection is, after all, a perfectly rational manner of proceeding. Why, if the individual is not prepared to invest in him- or herself, should the state step in and stump up? Perhaps this is the least unkind way of encouraging students to seek employment rather than going on to higher education! But students do not invest only in themselves. They invest in increasing their chances and earnings on a particular sector of the labour market. And the labour market, as employers, economists and experts of all hues have been telling us these five or more years past, is in a high state of flux, volatility and structural change, all subsumed under variously qualified historic processes, globalization being one, regional economic integration being a small edition of the same. Placed alongside one another, these two developments, the transformation of students into self responsible consumers plus the even greater unpredictability of the labour market in the industrial economies, let alone those emergent or submergent, inject yet another dimension of instability and hazard into the personal adventure of higher education.

\section{FINANCIAL DIVERSIFICATION}

This is not the only domain in which recent policies, whether fiscal or financial, have brought higher education into a high state of unpredictability. Such a condition is now in-built into those modes of funding higher education which follow from what is often termed "privatization". One of the more solid virtues which economists of all hues and especially those who observe the American higher education system, hold against state funding is the apparently fragile base it provides institutional autonomy. Better by far, they argue, to diversify one's funding sources, to play one off against the other. According to this reasoning, an institution may exercise a greater degree of real independence when its sources of finance are many. For if there is only one, dependence is complete and there is thus, little protection against arbitrary behaviour should untoward fancies seize the Prince or his servants. In short, the more sponsors, 
the less say they may effectively exercise. It is a powerful argument and many have been seduced by the success of the very system so often quoted in support of itnamely the American.

\section{PERVERSE EFFECTS}

Like many arguments pursued in abstracto or which refer to one "master system" as if that system were devoid of the very particular conditions, culture, history and circumstances that shaped the phenomenon in question, multiple sponsorship does not always beget institutional latitude or, for that matter automatically guarantee institutional stability. On the contrary, and this is surely the importance of Wield's exploration of the impact of donor funding in African universities, it can just as well work in the opposite direction-namely, to undermine long-term stability in pursuit of the short-term gain. Irrespective of whether the external funding sources or agencies are pleased to call themselves "donors", or are designated as "third party money streams", the situation he describes is of more than passing interest. For, in effect, because of the difficulties involved in public funding, African universities have long been faced de facto with having to deal with, and accommodate to, a situation not greatly different from those policies of privatization in the Northern hemisphere which embarrassed governments now wish higher education to embark upon. As core funding has become more precarious, so the funding of core functions - teaching, equipment, staff salaries etc.- - has moved increasingly over to what is ironically often alluded to as "soft money"--soft not in the sense of being easy to obtain, so much as in its precarious and short term nature. If "donors", industry or third party financing are held to be symbolic of the general process of "privatization", then it is evident that for many years African state sector universities have, perhaps unbeknown to themselves, been engaged in a de facto variant of a similar policy of financial diversification, relying less upon industry and a home-grown private sector finance so much a non-national edition of the same in the shape of donor agencies. Perhaps earlier than has been recognized, state universities in certain areas of Black Africa have, from the standpoint of their sources of finance, been heavily committed to "privatisation"- though for understandable reasons of national dignity this is neither willingly admitted on the part of the "receivers" nor greatly publicized as such by those who have given.

To be sure, such "external interests" are not surrounded to the same degree by the ideology of "consumerdom" or "response to society"s demands". Donors tend, after all, to be intermediaries even though they themselves justify the conditions attached to their donations by reference to their particular interpretations of a society's interests even though that society tends rarely to be their own.

\section{A NEW PERSPECTIVE}

Nevertheless, if we recast the relationship between "donors" and universities in terms less of "higher education policy in developing systems of higher education" than as a species of analogue which may serve to provide counter evidence to the blessings of receiving and financial diversification, we have the makings of an interesting debate and one which does not confine the basic issue of whether institutional latitude and initiative are advanced or undermined by financial diversification simply 
to the contemporary concerns of advanced economies. On the contrary, because the need for African universities to seek support for core activities from short term funding is far from being a recent phenomenon-though Weild's article suggests that it has now reached critical proportions - there is a wealth of historical evidence which, if examined less in the context of "donor development policy" than in the setting of the institutional consequences of the "offloading state", may well yield insights no less valuable for universities outside Africa and most especially those in Europe, whether West, Central or East.

Viewed within this perspective, namely the repercussions upon establishments of higher learning of having to rely on non public sources of finance, the African universities have a wealth of experience to offer their Northern counterparts and that in an area of the utmost importance and centrality. This is not to say that because absence of coordination amongst donor agencies has contributed significantly to fragmenting disciplinary development or made more difficult the steady pursuit of research priorities in African universities, that the same fate lies in store for those institutions which, elsewhere, have only just begun to move down this path. Any more than the opposite thesis which, looking towards the major research universities of the United States, takes the view that diversified sources of finance inevitably lead on to excellence and efficiency. There are, as in every contention of apparent simplicity, a large number of intervening and complicating factors between the enunciation of policy and intent and their outcome.

\section{ANOTHER DIMENSION}

There is, even so, another dimension involved in the nexus of giving and receiving and one which, increasingly, is beginning to attract attention, often within the context of institutional accountability to "external interests". As universities, in the words of the Good Book, "go forth into the highways and byeways that their (coffers) may be filled", so the number of interlocutors and interests with which they have to deal, expands out of all recognition. As a working hypothesis, one may state that the larger the gap to be filled between "core funding" and the revenue requirements of a given establishment, the larger the number of interlocutors. This is a formidable challenge indeed. Not only does it require that the individual university organize and formalize what hitherto was a largely informal process of gift-soliciting. It demands the setting aside of personnel and thus resources to this end, a task which assumes all the more importance as core activities themselves become reliant on such external, short-term backing. There is, by contrast with earlier times when dialogue was largely confined to the resource agencies of central government, be they Ministries or Research Councils, a species of fragmentation in the dialogue between university and the spiralling number of external interests, philanthropic, advocational, ethnic, community, business-interests that, if they do not necessarily require a formal account to be rendered, have nevertheless to be cultivated. Nor, if we bear in mind the behaviour of donor bodies in Africa, are such interests necessarily committed either to a stable series of priorities - they have their own backers to accommodate-nor, for that matter, are they committed to the same time frame as that of the university.

Naturally, there is much advantage to be had from laying down solid ties with future benefactors and with the local or regional communities as opposed to the national community mediated by formal regulated process which is the case with 
central government. But such ties raise the crucial question of how to reach a degree of accommodation which ensures that the donor tail does not wag the university dog or that the cacophony of conflicting demands, special pleading and requirements, does not exercise such leverage over the "responsiveness" of the university that its purpose is compromised in the medium, if not in the long term. The problem, to revert to an English cant expression, is not in the "quid" given, so much as in the "pro quo" that often accompanies, where it does not condition, the gift itself.

\section{CONCLUSION}

These are some of the more intractable issues which cut across the various articles in this issue of Higher Education Policy. They broach one of the central aspects with which universities are faced world wide, though the degree to which it presses down upon them is a matter of enormous variation, even within the limits of one country. So far, there has been little discussion, outside the assertion of fashionable orthodoxy which takes an optimistic and ideological view of an empirical situation namely, compressed university budgets - that explores the obverse side of the giving and receiving as it affects the way an institution develops. Perhaps as many believe, there is no alternative. But that does not discharge us from the responsibility of examining its likely consequences very closely, if only for the fact that an absence of alternative does not entail an absence of different options in pursuing it. 